\title{
P17 TRAINS BOATS AND PLANES
}

Barbara Henderson, Anne Steven Children's Hospice Association Scotland, Edinburgh, Scotland

10.1136/bmjspcare-2011-000105.17

Introduction Children's Hospice Association Scotland (CHAS) is a charity that is the sole provider of children's hospice services in Scotland for children and young people with life limiting conditions. CHAS at Home was developed to support families, across Scotland, at home in times of crisis, at end of life, and to support families who live in rural and remote areas. The journey to one of CHAS's two children's hospices can become impossible due to the child or young person's condition, or the distance making the journey impractical.

Aims CHAS aims to offer families a choice in their place of care, no matter where they live in Scotland; including the north, the islands; Orkney, Shetland and Hebrides. Scotland is 31510 sq miles in area, it is 274 miles long and has 130 inhabited islands.

Discussion For families who live a distance from their nearest hospice the journey can be traumatic for the child or young person especially as their condition deteriorates and their care needs increase. Imagine a $10 \mathrm{~h}$ journey, involving a ferry crossing, that includes administering medications, gastrostomy feeds, suctioning, personal care and more. All this can make the journey impractical and intolerable for the whole family. CHAS can relieve this by offering to take the ethos and care from the hospice to their home. A key to the success of this model of care is working in partnership with the local community teams. For the team providing this service it can mean a trip by train, boat or plane and nights away from home, however the team consider it a privilege to be able to support families in this way.

Conclusion CHAS is committed to providing a service to families wherever they live in Scotland no matter how remote. The families say "just to know that CHAS is there for us is amazing" 